\title{
REFLEXIONES NERVIOSAS Ené qué risas hisimos al pasar por el Sendeja: Sobre el humor y la risa ${ }^{1}$.
}

\author{
Juan Medrano \\ Médico Psiquiatra. Red de Salud Mental de Bizkaia. \\ oban@telefonica.net
}

\begin{abstract}
Nuestra cultura debe mucho a la teoría hipocrática de los humores. No es raro que en un contexto informal definamos el carácter de alguien como sanguíneo, colérico, atrabiliario o flemático, utilizando sin ser conscientes de ello términos e ideas del sabio médico de Cos. También, en cierto modo, nos convertimos en seguidores de Hipócrates cuando decimos de alguien que tiene mal humor, como si padeciera una peculiar discrasia que influyese en su actitud afectiva y emocional para con el mundo. E igualmente practicamos la Arqueofisiología cuando afirmamos que fulanito (o fulanita) está buen humor, atribuyéndole, sin saberlo, el gozo de acceder fugazmente a la felicidad a lomos de la adecuada homeostasis de sus humores corporales. Por el mecanismo que sea, nos hemos apoderado del término fisiológico hipocrático para definir un peculiar estado emocional o, por extensión, el conjunto de dichos, obras, conductas o situaciones, que desencadenan la risa o la sonrisa. Y lo hemos hecho porque reconocemos la existencia de una cualidad, una potestad netamente humana: lo que llamamos, trascendiendo ya a Hipócrates, el humor.
\end{abstract}

Como tal cualidad humana, las variantes del humor tienen dimensiones psicológicas e incluso semiológicas que podrían considerarse específicas. Encontramos un humor hueco, excesivo e inapropiado en el síndrome frontal; fácil, efervescente, espontáneo y a veces contagioso, en la manía; ausente hasta el punto de que el paciente es incapaz de reaccionar ante estímulos risibles, en la depresión; y antinórmico e idiosincrásico en la esquizofrenia, en la que parece existir un déficit en la percepción o apreciación del humor (1).

Uno de los más conocidos especialistas sobre la cuestión, Rod Martin (2), define al humor como un fenómeno cognitivosocial-afectivo. Para Martin, la dimensión afectiva del humor entraña una emoción positiva específica a la que llama "regocijo" (mirth), que resulta similar a otras emociones positivas como la alegría y la felicidad. Pero el regocijo incorpora una cualidad especial, característica, de "diversión", que lo diferencia. El regocijo aparece cuando en la evaluación cognitiva del entorno destaca lo que Martin llama "incongruencia jocosa", es decir: algo inusual, extraño, fuera de lo ordinario, o sorprendente, que debe además tener un elemento jocoso, un matiz de falta de seriedad. En el humor planificado se busca la incongruencia, se burlan los procesos mentales de quien escucha o lee, se les guía por una línea de razonamiento y se les lleva a expectativas que bruscamente chocan con un cambio del marco de referencia, en un choque que despierta la emoción del regocijo, cuya comunicación no verbal es la risa. Por último, el humor, en el modelo de Martin, es un fenómeno consustancialmente social. Los humanos nos reímos más en compañía, y el grueso de los chistes tiene que ver con situaciones sociales. 
MÁRGENES DE LA PSIQUIATRÍA Y HUMANIDADES

La incongruencia jocosa puede estar detrás de las risotadas con las que los niños pequeños reaccionan ante las caídas, tropiezos y golpes que configuran lo que en el cine clásico se llamaba slapstick. En cambio, los chiquillos no pueden desentrañar la sutileza de la ironía, el elemento cognitivo del humor. Pero enlazando lo cognitivo y lo social, lo que puede ser risible en una cultura carece del menor interés para otra, que puede juzgarlo incluso ofensivo.

Un árbitro se muere y se va al cielo. Le recibe un santo y le pregunta:

- ¿Y tú has sido bueno?

-Hombre, lo normal -responde el árbitro.

-¿Has pecado?

-Un poco".

-Cuéntame tus pecados -le dice el santo.

-Bueno pues una vez, en una final de Copa Real Madrid-Athletic de Bilbao, el Madrid ganaba 5-0 a falta de 5 minutos. Expulsé a 3 jugadores del Madrid, pité 6 penaltis inexistentes y acabó ganando el Athletic.

- ¿Y qué más? -insiste el santo.

-Pues otra vez, en el Camp Nou se jugaban la liga el Barcelona y el Athletic de Bilbao. Iban 0-0 y en el minuto 91 un jugador del Athletic hizo una tremenda entrada a uno del Barça, rompiéndole tibia y peroné. Expulsé al lesionado y pite penalti a favor del Athletic, que ganó la liga.

- Está bien, puedes entrar al cielo.

-Pero, oiga, ¿es que no me va a expulsar del cielo por esto?

-No te preocupes, hijo, está todo en orden.

-Muchas gracias, San Pedro

-No. San Pedro está de vacaciones, yo soy San Mamés

Por su parte, la risa es un fenómeno asociado muchas veces al humor, aunque no necesariamente se presenta siempre en situaciones humorísticas. Se trata, de hecho, de una descarga, un fenómeno con cierto paralelismo con la epilepsia, de modo que puede aparecer ante una estimulación eléctrica de ciertas áreas del cerebro, en el marco de ataques convulsivos o, de forma espontánea, inmotivada y liberada (desinhibida) en ciertas patologías neurológicas, de la cual el exponente más clásico es el síndrome pseudobulbar. También existe una variante epiléptica (epilepsia gelástica) cuyas crisis suelen comenzar con una risa superficial o vacía, que no transmite regocijo y que se presenta repentinamente, y sin un aparente estímulo jocoso. No es menos significativo que uno de los signos característicos del kuru es la risa compulsiva que hizo que en su momento se tildara a esta prionopatía de la enfermedad de la risa o la risa mortal.

La risa es un fenómeno social, y además, contagioso, hasta el punto de que se han descrito severas epidemias de risa, la más notable, en Tanganika (la parte continental de la actual Tanzania), iniciada en 1962. No fue aquel un episodio menor, ya que con intensidad fluctuante duró unos dos años y medio, afectó a unas mil personas y obligó a cerrar en algún momento hasta 14 colegios y escuelas. La epidemia se atribuyó a una especie de histeria de masas, que evidencia la contagiosidad de la risa, a su vez relacionada con las neuronas espejo (3). Otro ejemplo de contagio de la risa, si se quiere más banal, es el de las carcajadas enlatadas de las series televisivas. Tienen su origen en la costumbre de tener público en el plató o en los sets de rodaje, muy extendida en los primeros tiempos de la televisión, en los que gran parte de los programas se emitían en directo. El 9 de septiembre de 1950 debutó una serie, The Hank McCune Show, que sustituyó las risas del público por carcajadas grabadas. Aunque el programa duró solo tres meses en antena, ha pasado a la historia porque los productores televisivos descubrieron gracias a su 
iniciativa el poder de las risas enlatadas para generar ambiente jocoso en la audiencia. Ese es el motivo por el que ciertas series norteamericanas maquillan su escasa gracia y su humor más bien lacrimógeno con este truco.

No es nuestra especie la única que ríe. Dejando al margen la clásica referencia a la supuesta risa de las hienas, nuestros primos los grandes simios también se ríen en situaciones análogas a algunas de las que despiertan la risa en nosotros: el juego, la satisfacción o las cosquillas, algo que ya reconoció Darwin. Sin embargo, el mecanismo fisiológico y la acústica de su risa es diferente, ya que los humanos reímos al exhalar el aire y los simios, también al inhalar, y con unas vibraciones menos intensas de sus cuerdas vocales, por lo que su sonido se asemeja a una especie de jadeo. Dicho sea de paso, la diferencia entre nuestra risa y la de los grandes simios revela un mayor control fonatorio en nuestra especie, lo que a su vez implica una relación entre las características de la risa humana y la capacidad de producir lenguaje articulado.

La presencia de la risa en el chimpancé sugiere que apareció en un antepasado común, lo que nos permitiría datarla hace entre 5 y 7 millones de años. Sin embargo, si tenemos en cuenta que también hace risas el huraño y solitario orangután, con el que compartimos un antepasado más remoto, deberemos remontar la aparición de la risa hasta hace al menos 14 millones de años. El estudio de las características acústicas de la risa de los primates, por cierto, permite elaborar árboles filogenéticos superponibles a los filogramas y cladogramas elaborados por los medios habituales para relacionar las especies de primates (4). Incluso se ha podido precisar que en la historia de la evolución de la risa en los homínidos hubo dos puntos de desviación filogenética: uno en la separación de los orangutanes del resto de los grandes monos y otro en la de que tuvo lugar entre los pan (chimpancé y bonobo) y los homo.

Para Van Hoof (5), la base filogenética de la risa podría estar en la "expresión relajada con la boca abierta", que es una señal de juego, en la que la boca aparece abierta, los labios cubren los dientes superiores y el rostro y el cuerpo están relajados. La sonrisa podría en cambio derivarse de la "expresión silente con los dientes al descubierto", en la que el animal retrae los labios y los ángulos de la boca, descubriendo los dientes a la vez que mantiene la boca cerrada. Según Martin, la sonrisa es una señal de disposición amistosa en un animal de alto status, y de sumisión o apaciguamiento en un animal de bajo estatus. En los humanos la risa está asociada al humor, mientras que la sonrisa es más versátil, y puede usarse en su contexto filogenético, como señal de ánimo amistoso como señal de regocijo o diversión de baja intensidad en respuesta al humor.

Íntimamente relacionadas con la risa, las cosquillas son un fenómeno curioso, que se encuentra en diversas especies mamíferas, pero que solo los grandes primates y tal vez algunos monos son capaces de provocar (6). Su neurofisiología es incierta, ya que no se conoce ningún "receptor de cosquillas", por lo que se deduce que se construyen a nivel cerebral sintetizando diversas sensaciones. Se distinguen dos variedades: knismesis, sensación con un cierto toque sensual producida por una ligera caricia, como el roce de una pluma o el caminar de una araña sobre la piel, y gargalesis, mucho más intensa y generalmente placentera, que es la que provoca la carcajada típica en los niños. Lo más reseñable es que las cosquillas son heteroaplicadas, si vale el término, de manera que no es posible sentirlas cuando se las aplica uno mismo, sino que es necesario diferenciar como "otro" a quien las produce (7). Sin embargo, un hallazgo serendípico de Provine (8) su- 
MÁRGENES DE LA PSIQUIATRÍA Y HUMANIDADES

giere que podría ser necesario revisar esta cuestión. Este autor cuenta cómo, estando en la ducha, observó que era capaz de producir una sensación cosquillosa cuando se frotaba la planta de un pie con la mano contralateral, un descubrimiento que pudo replicar con un grupo de sujetos experimentales -indefensos alumnos de sus clases, como suele suceder en investigación psicológica-, que también percibían una mayor sensibilidad cuando la planta era estimulada por la mano contralateral, lo que por realizarse el estudio en el sobrio encuadre de un departamento universitario permitió descartar que lo observado por Provine en su ducha pudiera ser efecto de factores asociados confusionantes, como el uso de jabón o esponja, la humedad, la temperatura del agua o incluso la desnudez del experimentador. Provine sospecha que esto tiene que ver con el mayor retraso en la transmisión sensorial de la información contralateral respecto de la ipsilateral, de modo que es posible que ese decalaje fomente una mayor probabilidad de que el sistema nervioso central perciba como "otra" a la mano contralateral, surgiendo así la sensación de cosquilla.

Si sonrisa y la risa aparecen en otros primates, como respuesta a cosquillas o en situaciones placenteras, nos podemos cuestionar si también cabe encontrar en esas especies alguna forma o algún primordio del humor, como proceso cognitivo subyacente a la risa. Según De Waal (9), los chimpancés son capaces de bromear, de jugar con un toque humorístico, que les permite reunir información sobre el entorno social y tantear o explorar los límites de la autoridad. Algunos chimpancés y gorilas a los que se ha enseñado a comunicarse mediante lenguaje de signos son capaces de usar el lenguaje con connotaciones jocosas que recuerdan al humor, como juegos de palabras, insultos divertidos y usos incongruentes de palabras, a veces acompañados también por la risa jadeante de sus especies. Las formas de humor de los humanos son mucho más complejas, se basan en nuestra capacidad lingüística y cognitiva más desarrollada y en la habilidad para imaginar realidades alternativas, entender las mentes de otros -Teoría de la Mente- y comunicar ideas complejas mediante el lenguaje. El humano juega con todas estas capacidades cognitivas y lingüísticas a priori "serias", para producir situaciones humorísticas, manipulándolas por pura diversión. Esto sucede indefectiblemente en todas las culturas humanas, incluida la de los aborígenes australianos, que han permanecido aislados desde hace decenas de miles de años, por lo que hay que considerar al humor como un universal humano y cuya aparición se situó hace al menos 35.000 años (10).

La risa, en cualquier caso, no es una manifestación homogénea o uniforme. Szameitat y colaboradores comprobaron con RNMf que la risa que el oyente identifica como provocada por cosquillas se asocia con una excitación de la circunvolución temporal superior, mientras que la que los autores definen como emocional (la que el oyente identifica como vía de expresión de alegría o de burla), activaba el córtex frontal medial anterior (11). Los autores interpretan esta diferencia topográfico - funcional como indicativa de que la risa provocada por cosquillas tiene una mayor complejidad acústica, en tanto que la "emocional" refleja la participación de aspectos cognitivos más complejos relacionados con sus características sociales. La risa desencadenada por las cosquillas sería, pues, más elemental, más primitiva, y puesto que aparece en otros primates, menos evolucionada. Podemos seguir la diferenciación de la risa con la maduración del ser humano. Los niños pequeños aprecian las cosquillas y llegan a pedirlas. Disfrutan mucho con juegos de súbita des- 
aparición y aparición de personas conocidas (lo que en inglés se conoce como peekaboo), y como apuntábamos antes, sueltan grandes carcajadas con el slapstick de grandes golpes y caídas, muy posiblemente porque no son capaces de apreciar las sutilezas del humor verbal. En cambio, los adultos, con el pleno desarrollo del lenguaje simbólico, gozan más de un humor intelectual, irónico y no pocas veces sardónico, en el que el elemento cognitivo es mucho más notorio. Si tenemos en cuenta que en los primeros años del cine, la comicidad era típicamente slapstick, y pasó después, con el desarrollo del sonoro y la aparición del lenguaje verbal a intelectualizarse para poder expresar ironía, tendremos que concluir que la historia de la cinematografía cómica recapitula la ontogenia y la filogenia.

\section{Teorías sobre el humor y la risa}

El humor ha merecido el interés de los estudiosos desde hace muchos años. Filósofos notables le han dedicado su atención, avanzando hipótesis que sitúan la base del humor en la ilógica, la incongruencia, el contraste que, como hemos visto, Martin señala como uno de sus elementos fundamentales. En su "Critica del Juicio" (12), Kant sostiene que en todo lo que es capaz de desencadenar "fuertes estrépitos de risa", debe haber un elemento de absurdo, algo en lo que el entendimiento no puede hallar por sí mismo la satisfacción. La risa se experimentaría al desmoronarse la expectativa construida desde la lógica, algo que desengaña y frustra al entendimiento, pero que causa un regocijo momentáneo. A su vez, Schopenhauer (13) incide en la incongruencia como base del fenómeno humorístico, y sostiene que el humor surge ante el fracaso de un concepto para dar cuenta de un objeto de pensamiento. Cuando lo particular se impone a lo general, nos encontramos ante una incongruencia, que conlleva un elemento de sorpresa. Cuanto mayor y más inesperada sea la incongruencia, cuanto mayor sea la sorpresa, tanto más intensa y violenta será la risa. Por su parte, Bergson considera que la risa es un gesto social que castiga toda rigidez del espíritu, del carácter e incluso del cuerpo (14). La risa, para el filósofo y Nobel francés, surge cuando la forma se impone al fondo, cuando aparece esa rigidez, que es una forma de incongruencia. El humor es algo netamente racional; en sus palabras, "lo cómico, para producir su efecto, exige algo así como una momentánea anestesia del corazón. Se dirige a la inteligencia pura", por lo cual, no existiría fuera del ámbito estrictamente humano. Sería un mecanismo que actúa como correctivo social, ya que ayuda a las personas a identificar conductas desfavorables para el florecimiento y la prosperidad humanas. Todo lo que amenace con convertir a una persona en un objeto (animal o mecánico) es un material privilegiado para el humor.

También se ha propuesto que el humor guarda relación con la expresión reprimida de sentimientos agresivos o sexuales. La teoría más conocida al respecto es la de Freud (15), que sostiene que la risa y el humor sirven para liberar la tensión psíquica que provoca la represión de impulsos agresivos o sexuales de naturaleza inconsciente. La risa, por lo tanto es un fenómeno que por relajar la tensión es agradable, relajante y saludable. El chiste aúna el modelo de la incongruencia y la relajación, al mantener el interés y la tensión en quien lo escucha con una historia repetitiva que se alarga en una dirección, para resolverse de forma inesperada y jocosa.

Está Kim Jong Ul sentado en su oficina un día, cuando suena el teléfono. 
MÁRGENES DE LA PSIQUIATRÍA Y HUMANIDADES

-Buenos días, Kim, majo -dice una voz con un fuerte acento de Bilbao -Soy Gaizka, del bar Txiki en Bilbo y te llamo para informarte de que hemos decidido declararte oficialmente la guerra.

-Bien, Gaizka, responde Kim, qué noticia tan interesante. ¿Y de cuántos soldados disponéis?

-Por ahora, somos yo, mi primo Lander, su vecino Andoni, y el equipo completo de pelotaris del barrio. En total... jocho!

- A ver, Gaizka, creo que debería informarte de que tengo más de un millón de hombres en mi Ejército esperando mis órdenes para atacar.

- ¡Ostia! Creo que le tendré que volver a llamar. Hasta luego.

Al día siguiente, Gaizka llama otra vez.

-Oye, Kim, majo, nuestra declaración de guerra sigue en pie. Hemos conseguido algo de armamento de infantería.

- ¿Y de qué tipo de armamento estamos hablando, Gaizka?

-Tenemos el forfiesta de Andoni, la bicicleta de Lander y una grúa que le hemos robado a los municipales.

-Creo que debería informarte que yo tengo miles y miles de tanques y vehículos blindados para el transporte de tropas. Además, se me olvidó decirte ayer que tengo casi nueve millones de reservistas.

- ¿Cago en la leche! Le tendré que llamar otra vez, ;hasta luego!

Una vez más, Gaizka llama al día siguiente. -Kim, majo, mi declaración de guerra sigue firme. Hemos extendido nuestras fuerzas por mar y aire. Hemos conseguido atar un torpedo a la tabla de surf de Andoni y hemos montado un par de metralletas a un ultraligero que teníamos a mano. Además, se nos han unido 4 chavales aizkolaris, con hachas y todo. Le llamaba para avisarle y que se prepare.

Kim, tras guardar silencio, responde:

-Gaizka, te tengo que informar que yo tengo
1.000 bombarderos y 2.000 aviones de combate. Estoy haciendo pruebas con misiles de largo alcance con los que puedo pulverizar países enteros y no te voy a contar nada de ese arsenal que os pone tan nerviosos a los occidentales.

-Jesús, María ta José -responde Gaizkacreo que mañana le volveré a llamar.

Como ya venía siendo costumbre, Gaizka llama al día siguiente:

-Buenos días, Kim, majo. Siento informarte de que vamos a tener que cancelar la guerra. Retiramos nuestra declaración.

-Vaya, lo siento -responde Kim- ¿a qué se debe el cambio de opinión?

-Bueno -dice Gaizka -la verdad es que lo he comentado con los chavales en el bar, y hemos decidido que ni de coña vamos a ser capaces de dar de comer a 10 millones de prisioneros.

Otra línea de argumentación sostiene que el humor se usa para demostrar una posición de superioridad o para elevar el status social. La propuesta más conocida en este sentido es la clásica de Hobbes (16), para quien la "gloria súbita es la pasión que da lugar a esos gestos llamados RISA, y es causada por algún súbito acto propio que complace, o por la aprehensión de algo deformado en otro, por comparación con lo cual hay súbita autoaprobación". Hobbes sostiene que con frecuencia las personas que "son conscientes de las pocas habilidades que en ellos hay" utilizan la risa ante las imperfecciones ajenas como una especie de mecanismo compensatorio, con lo que concluye que "mucha risa ante los defectos de otros es un signo de pusilanimidad". Pero además de concebir al humor como un signo de superioridad o gloria, la teoría de Hobbes también permite entender ciertos tipos de humor como basados en el autodesprecio y en el resentimiento (17). 
Sea como fuere, el ser humano dedica un gran esfuerzo a la risa (con participación de más de una docena de músculos), lo que entraña un notable gasto de energía. También invierte mucho tiempo en actividades humorísticas, de las que evidentemente disfruta. El humor exige, además la participación de grandes recursos cognitivos -Rodden (18) enumera hasta doce-, lo que sugiere que tanta inversión solo ha podido seleccionarse si paga algún dividendo. Por lo tanto, cabe la pregunta de cuál es el valor añadido que aportan el humor y la risa.

Una primera línea de razonamiento tendría que ver con la dimensión saludable del humor, sobradamente conocida. El humor y la risa mejoran la autopercepción, la salud subjetiva e instilan optimismo, hasta el punto de que se han desarrollado técnicas orientadas a fomentarlos (risoterapia). Su efecto benéfico está documentado en textos bíblicos y en Galeno (19), y en la clínica y en la investigación se ha demostrado desde hace décadas la acción beneficiosa que la risa y el humor ejercen sobre diversas enfermedades. La risa podría mejorar la función inmunitaria, ya que estimula la actividad de las células NK e incrementa la concentración de la IgA salivar (20). También se ha comprobado el efecto positivo que la risa y el humor ejercen sobre diversos parámetros cardiovasculares (21), y se ha propuesto que este efecto tendría relación con la liberación de $\beta$-endorfinas (22). Aunque todas estas investigaciones adolecen de fallos y sobreentendidos (23), hay abundantes indicios de que la selección del humor podría derivarse de un efecto saludable en sí mismo.

Desde un paradigma más netamente evolucionista se han sugerido otras posibilidades. Alexander, incidiendo en la teoría hobbesiana de la superioridad, sugiere que el humor confiere un mayor éxito reproductivo porque incrementa el status propio al arrinconar y ridiculizar a otros (24). Según este modelo, las principales ventajas de contar chistes o hacer bromas son aumentar el status propio y rebajar el de otros. No hay, de hecho, mejor expresión de esta función de la risa que las crueles carcajadas proferidas en situaciones en que se unos humanos victimizan a otros (asaltos, torturas, violaciones y todo el conjunto de tropelías y maldades exhibidas, por ejemplo, en las guerras), o el regocijo con el que las masas asistían a las ejecuciones públicas siglos atrás. El mismo autor señala otra función del humor: la de elevar el las personas a quienes se cuenta los chistes, potenciándose así la camaradería y la unidad social. Esta última función tendría un elemento cohesivo, que podría contribuir a un mismo tiempo a reforzar los vínculos en el endogrupo y ridiculizar al exogrupo. Podría así explicarse el uso del humor no solo para expresar, sino para potenciar la rivalidad, muy común a lo largo de la Historia, y de la cual conocemos múltiples ejemplos cotidianos y relativamente benignos, como los chistes que cuentan los bizkainos sobre gipuzkoanos, idénticos a los que los gipuzkoanos relatan sobre los bizkainos, lo que implica que un determinado hallazgo humorístico puede ser apreciado por distintos colectivos humanos, y utilizado por todos ellos para zaherir al vecino cambiando el origen de sus protagonistas.

Un vitoriano baja por la autopista de hacia Bilbao al volante de su flamante coche nuevo. Tan contento y ufano circula que en un despiste se le va el coche hacia el arcén y termina con la carrocería hundida al chocar con el quitamiedos. Sale del coche y se lamenta de su mala suerte. Al poco, se detiene un coche con matrícula de Bilbao:

-¿Qué te ha sucedido, hombre?

-Pues mira, iba conduciendo, se me ha ido el coche y, qué mala suerte, me he dado contra 
el quitamiedos y ahí ves, toda la carrocería hundida. Y lo peor es que acabo de estrenarlo.

-No te preocupes, hombre-le contesta el bilbaino-lo que tienes que hacer es agacharte y soplar fuerte, fuerte, por el tubo de escape. Ya verás cómo se va el bollo y la carrocería vuelve a su ser.

- ¿Estás seguro? ¿No me estarás tomando el pelo?

-Qué va, hombre... es más: me quedaría a ayudarte a soplar si no fuera porque ando con prisa. Ya te digo, sopla fuerte, fuerte, sin parar, y ya verás cómo lo solucionas.

$Y$ el bilbaino se marcha dejando al vitoriano en la faena. Desgañitado, sin resuello, después de mucho soplar, ve que la carrocería sigue tan hundida como en un principio.

-Maldito bilbaino, me ha tomado el pelo-se lamenta.

Al poco, se detiene un coche con matrícula de Donosti.

- ¿Qué te ha pasado, hombre?

-Pues mira, iba conduciendo, se me ha ido el coche y, qué mala suerte, me he dado contra el quitamiedos y ahí ves, toda la carrocería hundida. Y lo peor es que acabo de estrenarlo. Y para rematarlo, se para un bilbaino, me dice que lo que tengo que hacer es soplar por el tubo de escape y me he quedado sin aliento haciendo el tonto, por hacerle el caso. Se estará riendo de mí el muy piiiiiiii.

El guipuzcoano le mira pensativo, rodea el coche y con expresión triunfante, le dice:

-Pero bueno, ;cómo esperas por mucho que soples que la carrocería se desabolle si llevas la ventanilla bajada!

Otras propuestas sitúan más claramente el sentido y la función del humor en elementos sociales o grupales. La teoría de Weisfeld (25) plantea que el humor proporciona a los otros una información social valiosa, al tiempo que la risa provo- ca sentimientos agradables que refuerzan positivamente al humorista. Además de ver su conducta y su rol potenciados, el cuentachistes consigue con su función jocosa aliados potenciales, lo que le depara una ventaja para el futuro. Por su parte, Barret y colaboradores plantean que el humor sustituyó al placer del despiojamiento o acicalamiento social que se observa en los primates (26). El humor y la risa serían así un paso previo y un factor que favorecería el desarrollo del lenguaje. En su teoría del ojo interno, Jung sostiene que la risa y el humor son un instrumento de cooperación entre humanos (27).

Para Martin (2) el humor nació del juego de los mamíferos como un mecanismo para realzar la emoción positiva y la cohesión social. Se ha demostrado que las emociones positivas, incluido el regocijo, son capaces de potenciar funciones cognitivas como el pensamiento flexible, la resolución de problemas, la memoria y la creatividad, además de ciertas conductas prosociales como la disposición a ayudar y la generosidad (28). Obviamente, en una especie social como la nuestra, todas estas mejoras serían adaptativas. Por lo tanto, Martin considera que el humor es una extensión cognitivo-lingüística del juego social. En su opinión, los humanos habríamos ampliado las funciones del juego, el regocijo y la risa, que como hemos visto, están presentes en algún grado en otros primates, para conseguir así desarrollar la capacidad de jugar con las ideas, las palabras y las realidades alternativas mediante el humor.

Con independencia de todas estas propuestas, en el marco de la convivencia social el humor se concibe como una mecanismo de defensa muy maduro, que según Boulton y Smith convierte la confrontación problemática en juego, de modo que ninguna de las partes implicadas necesita competir seriamente y se evitan los riesgos que la disputa conlleva (29). El humor así sería un mecanismo que 
hace que se pueda ceder ante un competidor sin por ello admitir un status inferior.

Otro enfoque supone que el humor es un instrumento útil para demostrar creatividad y capacidad como pareja (30). En otros términos, el humor es sexualmente atractivo, como se deduce de algunos estudios (31). Las mujeres afirman que buscan una pareja con sentido del humor con mayor frecuencia que los varones, quienes de forma complementaria tienen una mayor tendencia a contar chistes que las mujeres. También estas sonríen a sus contertulios masculinos con más frecuencia que a la inversa. Las mujeres prefieren una pareja que las haga reír y los varones desean que su pareja sea capaz de apreciar su sentido del humor (8). Asimismo, se ha comprobado experimentalmente que el humor se asocia a una mayor inteligencia general, y que es percibido como tal por el observador (32). Se trataría, por lo tanto, de un marcador, de un rasgo que informaría de una cualidad apreciada que realzaría las probabilidades de la persona jocosa para obtener pareja.

Greengross y Miller (33) han estudiado el humor que se expresa mediante autodesprecio desde un punto de vista evolucionista y centrado en el individuo. En un estudio con estudiantes observaron que este tipo de humor resulta atractivo cuando se percibe en personas de status alto, y en este sentido, puede favorecer la selección sexual. En cambio, en las personas cuyo status se percibe como bajo, el autodesprecio humorístico es considerado no atractivo. Los autores interpretan estos resultados a la luz de la Teoría del Handicap de Zahavi (34), en cuanto que el individuo con un status elevado, al exhibir una limitación, puede "permitirse" rebajarlo humorísticamente.

La teoría de la falsa alarma de Ramachandran (35-38) sobre la risa agrupa alguno de los elementos anteriores. Según este autor, todas las bromas y los "incidentes divertidos" comparten una misma estructura lógica. Quien cuenta o plantea el chiste provoca en quien lo escucha o presencia una creciente tensión, para al final introducir un giro inesperado que entraña una plena reinterpretación de todos los datos previos. Esta nueva interpretación, aunque sea inesperada, es tan compatible con los datos aportados como la que originalmente podría esperar quien escucha el chiste. Por eso los chistes y bromas tienen mucho en común con la creatividad científica y con lo que Kuhn denominó "cambio de paradigma" en respuesta a una única anomalía. En el caso del chiste esta anomalía es el remate, el "golpe" jocoso, que solo hará reír si quien lo escucha capta o "pilla" su sentido y significado. En términos de Ramachandran (37), si es capaz de apreciar en un "flash de insight" cómo una interpretación nueva y completamente diferente del enunciado del chiste permite incorporar y aceptar el final del mismo, inesperado, anómalo y jocoso. Entre las muchas situaciones que obligan a un cambio de paradigma para encajar la anomalía, Ramachandran propone que pensemos en alguien que estando de noche en la cama oye golpes. Inicialmente se los explica a sí mismo como efecto del viento, pero si de pronto suena un golpe más cercano y más intenso, la anomalía requiere una reinterpretación, un cambio de paradigma, algo que refute la interpretación inicial de que era el viento el motivo de los ruidos. Por ejemplo, nuestro hipotético durmiente puede pensar que hay ladrones en la casa. Se levanta, va a explorar y de pronto descubre que el gato ha tirado un jarrón. Es una nueva anomalía, una nueva explicación o interpretación ante la que nuestro protagonista reacciona riendo. Y este es el meollo de la cuestión para Ramachandran: para que un chiste o un hecho sea jocoso debe producirse un cambio de paradigma de consecuencias 
triviales, que a nivel neuropsicológico surge del diálogo entre la tendencia del hemisferio izquierdo a encontrar e imponer consistencia en los datos que recibe, y los mecanismos orientadores del hemisferio derecho (36). Este modelo, por cierto, tiene un paralelismo con las teorías previamente expuestas sobre la incongruencia como base del humor.

El slapstick de caídas, de golpes, que caracterizaba a los Keystone Cops, es un ejemplo del reajuste hacia la anomalía de consecuencias triviales. Una persona que se caiga y se dé aparentemente un serio batacazo no provoca la risa, pero alguien que caiga sistemáticamente, sea capaz de levantarse para volver a caerse, manteniendo una actitud cómica y en absoluto doliente, representa una anomalía risible. De ahí que se reaccione ante los cortos de Mack Sennett con risa.

Siguiendo a Ramachandran, desde el punto de vista evolutivo, el propósito de la risa sería permitir a un individuo alertar a otros miembros de su grupo social (generalmente con los que se comparten genes) de que ha detectado una anomalía trivial. Al reír, pues, se informa de que se ha descubierto una falsa alarma; los humanos, en los albores de nuestra especie, avisaban, mediante la risa, de que a pesar de que inicialmente podría parecer lo contrario, en realidad no es así (anomalía: cambio de paradigma) y no hay motivo de preocupación. Resulta sugestivo, en este sentido, que como ya señalara Darwin, las zonas más sensibles a las cosquillas son precisamente áreas expuestas a ataques de predadores (el cuello, el abdomen, los flancos, las plantas de los pies). Por otra parte, hacer cosquillas es un gesto al mismo tiempo un equivalente a un ataque por su actitud y pose, y un deleite para el niño. Todo ello sugiere que las zonas sensibles están también preparadas y dispuestas a detectar y avisar de que un contacto táctil es una falsa alarma.

En el peekaboo, el juego de la desa- parición y aparición que tanto embelesa a los niños pequeños, podemos encontrar una reminiscencia de la falsa alarma. La desaparición del adulto, de la figura con quien se tiene el apego, es algo preocupante, que despierta la angustia. Pero si de pronto ese "mayor" reaparece, dobla la esquina y asoma la cabeza, el infante se encuentra ante una anomalía de consecuencias triviales. No ha perdido a su figura de apego, que vuelve súbitamente para tranquilidad, alivio y goce del niño, por lo que surge la risa. No es de extrañar que Ramachandran (38) califique a este juego de "cosquillas cognitivas".

En cuanto a la sonrisa, Ramachandran (37) plantea la hipótesis de que en un encuentro casual entre dos primates ancestrales la primera reacción sería ensañar los dientes en un gesto amenazante. Sin embargo, si esos dos individuos se reconocían como miembros de un mismo grupo, o como amigos o parientes, ese gesto se quedaría a medio camino, configurando la sonrisa. Para nuestro autor, sería una forma de saludo ritualizado, que transmitiría el mensaje "sé que no supones una amenaza para mí, y te hago saber que yo tampoco lo soy para ti".

¿Cómo se pasa de la risa como noticia de falsa alarma al humor? Ramachandran vincula la detección de la anomalía con las teorías previas que defienden que la base del humor es la percepción de una incongruencia. A su vez, la capacidad de sacar punta a los datos, de hacer chistes a partir de situaciones reales, de ironizar, supone un esfuerzo mental y creativo que hace que el humor sea un mecanismo para ejercitar la inteligencia, con lo que sería adaptativo. Aunque Ramachandran no lo plantee en estos términos, también podemos entender que la noticia de que se trata de una falsa alarma comunicada mediante la risa es algo a festejar, algo gozoso, digno de ser celebrado. De ahí pueden surgir tanto la dimensión hedónica de la risa 
y el humor como el hecho de que se haya preservado y dirigido hacia actividades no ya de supervivencia del grupo, sino de mero disfrute. En cualquier caso, el humor está indisolublemente vinculado a la risa. Por eso son patológicas las risas inmotivadas. O por eso, como sucede en algunos casos clínicos, la risa provocada por la estimulación eléctrica de ciertas zonas cerebrales "obliga" a la persona afectada (o más precisamente a su hemisferio dominante) a buscar en su entorno posibles desencadenantes jocosos con los que explicar(se) el ataque de risa, y a afirmar que son ellos los causantes de su hilaridad aunque objetivamente carezcan de cualquier gracia (39); otra evidencia de lo que Gazzaniga llamó "el intérprete del hemisferio izquierdo".

Pero en situaciones de alarma plena y confirmada, donde no hay esperanza de que cambie el paradigma ni la situación de amenaza, el humor puede tener efectos saludables y favorecer la supervivencia. Chaya Ostrower (40) estudió en su tesis doctoral el papel del humor como mecanismo de defensa durante el holocausto. Para ello entrevistó a una serie de supervivientes, que le relataron sus experiencias, así como ejemplos de lo que en aquel entonces servía de descarga risible para las víctimas de la barbarie nazi. A la luz de las teorías de Avner Ziv (41), que a la sazón supervisó la tesis, distinguió cinco funciones del humor durante el Holocausto: la agresiva (frente a los verdugos), la sexual (en la que incluyó una variante escatológica), la social - cohesiva, la defensiva (en la que las particulares condiciones de los campos de exterminio le invitaron a incluir los chistes sobre la comida) y la intelectualizadora. Las conclusiones de su trabajo son interesantes. Las personas con sentido del humor, concluye, fueron capaces de mantenerlo a lo largo de su tormento y también después de ser liberadas. El humor servía para encarar las situaciones dramáticas o la confrontación con la muerte, sin negar su gravedad. Mención especial merece la referencia a una variante de la función de mecanismo de defensa consistente en lo que Ostrower llama "humor sobre uno mismo", muy presente en la sociedad y cultura judías. Resulta ilustrativo uno de los chistes que intercambiaban las propias víctimas:

Dos judíos hambrientos se encuentran en Varsovia; uno de ellos está bebiendo colonia; el otro le dice:

-Moyshe, ¿Por qué haces eso?

-Así oleré mejor cuando me conviertan en jabón- responde Moyshe.

Este breve relato, que parece un ejemplo de fortaleza moral, capacidad de autocrítica y disposición a reírse de uno mismo, tendría unas connotaciones muy diferentes si lo contase un verdugo nazi. No podría sonarnos sino a ridiculización, denostación, menosprecio; en ese caso el humor desempeñaría la función que Ziv llama agresiva o ejemplificaría el señalamiento de diferencia de status que apunta Alexander. Pero cuando es la víctima quien hace el chiste nos encontramos ante la función autodeprecatoria del humor, intuida ya por Hobbes y que hemos visto que puede tener valor para obtener pareja. Esta dimensión negra en torno a uno mismo pudo también ser saludable en situaciones tan extremas como las de Auschwitz.

Por lo tanto, el mismo chiste tiene un efecto diferente si es un "autochiste" en que uno ironiza sobre sí mismo o si lo cuenta otro. Es posible que la sonrisa que provoca el autochiste se torne en rictus de desagrado si la misma historia la cuenta un enemigo, un rival o el vecino. Da la impresión de que a la hora de someternos a la crítica, a los seres humanos nos resulta más reconfortante el espejo de la conciencia, que la opinión 
MÁRGENES DE LA PSIQUIATRÍA Y HUMANIDADES

ajena. La autocrítica tiene algo de voladura controlada, mientras que el juicio externo amenaza con la demolición del edificio de nuestra imagen. Nuestra resistencia a encararlo, seguramente, es tan humana como la propia risa.

\section{BIBLIOGRAFÍA:}

(1) Polimeni JO, Campbell DW, Gill D, Sawatzky BL, Reiss JP.Diminished humour perception in schizophrenia: relationship to social and cognitive functioning. J Psychiatr Res 2010; 44: 434-40 [Abstract en: http:// www.ncbi.nlm.nih.gov/pubmed/19892368].

(2) Martin RA. Psicología del humor: un enfoque integrador. Madrid: Orión, 2008.

(3) Dossey L. Strange contagions: of laughter, jumps, jerks, and mirror neurons. Explore (NY) 2010; 6: 119-28 [Texto completo en: http://download.journals. elsevierhealth.com/pdfs/journals/1550-8307/ PIIS1550830710000352.pdf].

(4) Davila Ross M, Owren MJ, Zimmermann E. Reconstructing the evolution of laughter in great apes and humans. Curr Biol 2010; 19: 1106-11 [Texto completo en: https://scienceweb.madison.k12.wi.us/files/ science/Evolution_of_Laughter.pdf].

(5) Van Hooff JP. A comparative approach to the phylogeny of laugher and smiling. En Hinde RA, editor. Nonverbal Communication. Cambridge: Cambridge University Press; p. 209-241, 1972

(6) Leavens DA. Animal communication: laughter is the shortest distance between two apes. Curr Biol 2009; 19: R511-3 [Texto completo en: http:// postcog.ucd.ie/files/Laughingapes.pdf].

(7) Blakemore SJ, Wolpert DM, Frith CD. Central cancellation of self- produced tickle sensation. Nat Neurosci 1998; 1: 635-40 [Texto completo en: http://wexler. free.fr/library/files/blakemore\%20(1998)\%20 central\%20cancellation $\% 20$ of\%20selfproduced $\% 20$ tickle $\% 20$ sensation.pdf].

(8) Provine RR. Curious behavior. Cambridge, Massachussets: Belknap Press, 2012

(9) De Waal F. La política de los chimpancés. Madrid: Alianza Editorial, 1998

(10) Polimeni J, Reiss JP. The First Joke: Exploring the Evolutionary Origins of Humor. Evol Psychology 2006; 4: 347-66 [Texto completo en: http://www.epjournal. net/wp-content/uploads/ep04347366.pdf].

(11) Szameitat DP, Kreifelts B, Alter K, Szameitat AJ, Sterr A, Grodd W et al (2010). It is not always tickling: distinct cerebral responses during perception of different laughter types. Neuroimage; 53:1264-71 [Abstract en: http://www.ncbi. nlm.nih.gov/pubmed/20600991].

(12) Kant I. Crítica del juicio. Madrid: Espasa-Calpe, 2007

(13) Schopenhauer A. El mundo como voluntad y representación. Madrid: Trotta, 2003.

(14) Bergson H. La risa: ensayo sobre la significación de lo cómico. Madrid: Alianza Editorial, 2008.

(15) Freud S. El chiste y su relación con lo inconsciente. En Freud S. Obras completas de Sigmund Freud (Traductor: L. Ballesteros y de Torres), cuarta edición. Madrid: Nueva, p. 1029-167, 1981.

(16) Hobbes T. Leviatán. Madrid: Alianza Editorial, 1996.

(17) Valbuena de la Fuente F. El humor en Thomas Hobbes. CIC (Cuadernos de Información y Comunicación) 2002; 7: 47-51 [Texto completo en: http://revistas. ucm.es/index.php/CIYC/article/view/ CIYC0202110047A/7336].

(18) Rodden FA. The funny meat 
MÁRGENES DE LA PSIQUIATRÍA Y HUMANIDADES

behind your eyes. En Cohen H, Stemmer $\mathrm{B}$, editores. Consciousness and Cognition: Fragments of Mind and Brain. Amsterdam: Academic Press (Elsevier), 2007

(19) Bennett MP, Lengacher C. Humor and Laughter May Influence Health IV. Humor and Immune Function. Evid Based Complement Alternat Med 2009; 6: 159-64 [Texto completo en: http://acmd615.pbworks. com/f/Humor2.pdf].

(20) Bennett MP, Lengacher CA. Humor and laughter may influence health. I. History and background. Evid Based Complement Alternat Med 2006; 3 :61-3 [texto completo en: http:// digitalcommons.wku.edu/cgi/viewcontent. cgi?article=1000\&context=nurs_fac_pub].

(21) Sugawara J, Tarumi T, Tanaka H. Effect of mirthful laughter on vascular function. Am J Cardiol 2010; 106: 856-9 [Texto completo en: http://dept. wofford.edu/neuroscience/NeuroSeminar/ psfSpring2013/1-s2.0-S0306987709002898main.pdf].

(22) Miller M, Fry WF. The effect of mirthful laughter on the human cardiovascular system. Med Hypotheses 2009; 73: 636-9 [Texto completo en: http://dept. wofford.edu/neuroscience/NeuroSeminar/ psfSpring2013/1-s2.0-S0306987709002898main.pdf].

(23) Martin RA. Humor, laughter, and physical health: methodological issues and research findings. Psychol Bull 2001; 127: 504-19 [Texto completo en: http://users. skynet.be/bs939021/artikels/humor\%20 laughter\%20physical\%20health.pdf].

(24) Alexander RD. Ostracism and indirect reciprocity: the reproductive significance of humor. Ethol Sociobiol 1986; 7: 253-70 [Texto completo en: http://deepblue.lib.umich.edu/bitstream/ handle/2027.42/26385/0000472. pdf?sequence $=1$ ].
(25) Weisfeld G. The adaptive value of humor and laughter. Ethol Sociobiol 1993; 14: 141-69 [Abstract en: http://www.journals. elsevierhealth.com/periodicals/ensold/article/ PII0162309593900127/abstract].

(26) Barrett L, Dunbar R, Lycett J. Human Evolutionary Psychology. Princeton: Princeton University Press, 2002.

(27) Jung WE. The Inner Eye theory of laughter: Mindreader signals cooperator value. Evol Psychology 2003; 1: 214-53 [Texto completo en: http://www.epjournal. net/wp-content/uploads/ep01214253.pdf].

(28) Isen AM. Missing in action in the AIM: Positive affect's facilitation of cognitive flexibility, innovation, and problem solving. Psychol Inq 2002; 13: 57-65 [Texto completo en: http://homepages.uwp.edu/crooker/745Resile/articles/Isen-2002-x.pdf].

(29) Boulton, M.J., Smith, P. K. (1992). The social nature of play fighting and play chasing: Mechanisms and strategies underlying cooperation and compromise. En Barkow JH, Cosmides L Tooby J (Eds.): The adapted mid: Evolutionary Psychology and the generation of culture. New York: Oxford University Press.

(30) Miller GF. The mating mind: How sexual choice shaped the evolution of human nature. New York: Doubleday, 2000.

(31) Mora-Ripoll R, Ubal-López R. La risa: diferencias según el género. Rev Clin Esp 2011; doi: 10.1016/j.rce.2010.10.013 [Texto completo en: http://www.elsevier. es/sites/default/files/elsevier/eop/S00142565(11)00114-7.pdf].

(32) Howrigan DP, Mc Donald. Humor as a Mental Fitness Indicator. Evol Psychology 2008; 6: 652-66 [Texto completo en: http://www.epjournal.net/wp-content/ uploads/ep06652666.pdf].

(33) Greengross G, Miller GF. Dissing Oneself versus Dissing Rivals: Effects of Status, Personality, and Sex on the Short- 
MÁRGENES DE LA PSIQUIATRÍA Y HUMANIDADES

Term and Long-Term Attractiveness of SelfDeprecating and Other-Deprecating Humor. Evol Psychology 2008; 6: 393-408 [Texto completo en: http://www.psychologytoday. com/files/attachments/95822/self-deprecatinghumor-is-sexually-attractive.pdf].

(34) Zahavi A. Mate selection: a selection for a handicap. J Theor Biol 1975; 53: 205-214 [Texto complet0 en: http:// www.eebweb.arizona.edu/faculty/dornhaus/ courses/materials/papers/other/Zahavi\%20 sexual $\% 20$ selection $\% 20$ handicap $\% 20$ model\%20signal.pdf].

(35) Ramachandran VS. Anosognosia in parietal lobe syndrome. Conscious Cogn 1995; 4: 22-51 [Texto complete en: http://pacherie.free.fr/COURS/MSC/ Ramachandran_1995.pdf].

(36) Ramachandran VS. The evolutionary biology of self-deception, laughter, dreaming and depression: some clues from anosognosia. Med Hypotheses 1996; 47: 347-62 [Texto completo en: http:// leftinthedark.org.uk/PDF/Ramachandran $\% 20$ VS\%20Evol.pdf].

(37) Ramachandran VS. The neurology and evolution of humor, laughter, and smiling: the false alarm theory. Med Hypotheses 1998; 51: 351-4 [Abstract en: http://www.ncbi.nlm.nih.gov/ pubmed/9824844].

(38) Ramachandran VS. Lo que el cerebro nos dice. Los misterios de la mente humana al descubierto. Barcelona: Planeta, 2011.

(39) Fried I, Wilson CL, MacDonald KA, Behnke EJ.Electric current stimulates laughter. Nature 1998; 391: 650 [Abstract en: http://www.nature.com/nature/journal/v391/ n6668/abs/391650a0.html] .

(40) Ostrower C. Humor as a defense mechanism in the Holocaust. Thesis confirm by the Senate of Tel-Aviv University to conferred the Degree "Doctor of Philosophy". January 2002 [Texto completo en: http://web. macam98.ac.il/ ochayo/absractn.pdf].

(41) Ziv A, Gadish O. The disinhibiting effects of humor: aggressive and affective responses. Humor 1990; 3: 247-58 [Abstract en: http://www.deepdyve.com/ lp/de-gruyter/the-disinhibiting-effects-ofhumor-aggressive-and-affective-responsesJ9OMnBCSrh]. 